\section{Defining Borderline Resectable Pancreatic Cancer: Emerging Consensus for an Old Challenge}

\author{
Mokenge P. Malafa, MD
}

The designation of a patient as having borderline resectable pancreatic ductal adenocarcinoma (PDAC) presents a significant clinical challenge because of the existence of multiple definitions and the lack of a standard treatment approach. Pancreatic cancer presents as a continuum, from resectable local disease, to locally advanced unresectable disease because of the involvement of surrounding critical vascular structures. Since the 1990s, a subset of patients between resectable and locally advanced has been recognized. Initially referred to as marginally resectable pancreatic cancer, NCCN coined the term borderline resectable pancreatic cancer to define these patients in its annual guidelines, first published in $1997 .{ }^{1}$

Borderline resectable PDAC is best conceptualized as tumors that involve the adjacent vasculature to a limited extent and those for which resection, although possible, will likely be compromised by positive surgical margins in the absence of vascular resection and reconstruction. Of the 338,000 new cases of PDAC diagnosed worldwide, only an estimated $15 \%$ to $20 \%$ of patients have potentially resectable disease at diagnosis. Approximately $40 \%$ have distant metastases, and another $30 \%$ to $40 \%$ have locally advanced unresectable tumors.

Because surgical resection offers the only chance of cure for nonmetastatic pancreatic cancer, declaring a patient's disease unresectable is an assignment to therapy without a significant chance for survival beyond 5 years. Consequently, in addition to identifying resectable PDAC, it is important to differentiate borderline resectable PDAC from locally advanced unresectable cancer, because some patients with borderline resectable PDAC can undergo curative resection with similar outcomes to those with resectable disease. Moreover, following current systemic therapy regimens, some patients with locally advanced unresectable PDAC are downstaged to borderline resectable disease and can undergo successful resection of their disease. Therefore, it is a welcome development that there is increasing consensus about the definition of borderline resectable PDAC.

Since the 1997 NCCN definition of resectable, borderline resectable, and unresectable PDAC in the NCCN Guidelines for Pancreatic Adenocarcinoma, ${ }^{1}$ their definition has evolved in a deliberate attempt to align with other recent consensus definitions (Table 1). ${ }^{2}$ In 2009, a consensus conference sponsored by the Americas Hepato-Pancreato-Biliary Association (AHPBA) and co-sponsored by the Society for Surgery of the Alimentary Tract (SSAT), the Society of Surgical Oncology (SSO), the gastrointestinal symposium steering committee, and The University of Texas MD Anderson Cancer Center published an expert consensus statement defining resectable and borderline resectable PDAC. ${ }^{3}$ NCCN endorsed this definition, which differs from the NCCN definition only in the degree of tumor involvement of the superior mesenteric vein-portal vein (SMV-PV).

In the AHPBA/SSAT/SSO definition, all tumors with any degree of abutment or encasement of the SMV-PV are considered borderline resectable. In contrast, the NCCN definition requires distortion of the SMV-PV for the tumor to be considered borderline resectable. By this definition, the absence of evidence of peritoneal or hepatic metastases following a thorough radiologic assessment is a criterion for both resectable and borderline resectable disease. The NCCN Pancreatic Adenocarcinoma Guidelines Panel defines patients with resectable disease as those who have clear fat

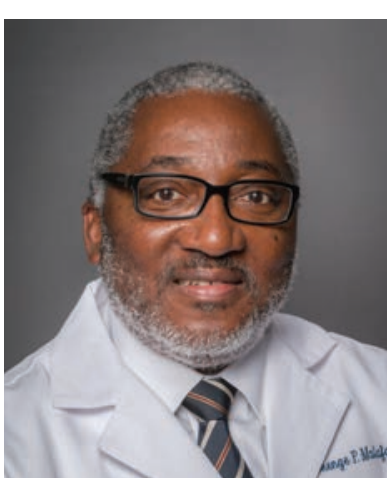

Mokenge P. Malafa, MD

Mokenge P. Malafa, MD, is Professor and Chair of the Department of Gastrointestinal Oncology Department at the Moffitt Cancer Center. He has served as the Vice-Chair of the NCCN Guidelines Panel for Pancreatic Adenocarcinoma since 2013 and has been an active member of the NCCN Guidelines Panel for Hepatobiliary Cancers since 2004.

He obtained his BS from the University of Wisconsin Green Bay and his MD from the University of Wisconsin Medical School. He completed his general surgery residency at the Medical College of Ohio and surgical oncology fellowship at the City of Hope National Medical Center in California. He is board certified with the American Board of Surgery.

$\mathrm{He}$ is a physician scientist with a clinical focus on the management of patients with pancreatic cancer and hepatobiliary malignancies. His primary research interest is the prevention of pancreatic cancer development and relapse with novel compounds including micronutrients, such as vitamin E tocotrienol. $\mathrm{He}$ also studies noninvasive detection of high-risk cystic neoplasms of the pancreas and predictive biomarkers of resected pancreatic cancer.

The ideas and viewpoints expressed in this editorial are those of the author and do not necessarily represent any policy, position, or program of NCCN. 


\begin{tabular}{|c|c|c|c|c|c|}
\hline & NCCN $1997^{1}$ & NCCN $2014^{2}$ & AHPBA $^{3}$ & MD Anderson ${ }^{13}$ & Alliance $^{5}$ \\
\hline $\begin{array}{l}\text { SMV- } \\
\text { PV }\end{array}$ & $\begin{array}{l}\text { Severe unilateral } \\
\text { SMV/portal } \\
\text { impingement }\end{array}$ & $\begin{array}{l}\text { Venous } \\
\text { involvement } \\
\text { of the SMV } \\
\text { or PV with } \\
\text { distortion or } \\
\text { narrowing of } \\
\text { the vein or } \\
\text { occlusion of } \\
\text { the vein with } \\
\text { suitable vessel } \\
\text { proximal } \\
\text { and distal, } \\
\text { allowing } \\
\text { for safe } \\
\text { resection and } \\
\text { replacement }\end{array}$ & $\begin{array}{l}\text { Venous } \\
\text { involvement } \\
\text { of the SMV/PV } \\
\text { demonstrating } \\
\text { tumor abutment } \\
\text { with or without } \\
\text { impingement } \\
\text { and narrowing } \\
\text { of the lumen, } \\
\text { encasement of } \\
\text { the SMV/portal } \\
\text { but without } \\
\text { encasement of the } \\
\text { nearby arteries, } \\
\text { or short segment } \\
\text { venous occlusion } \\
\text { resulting from } \\
\text { either tumor } \\
\text { thrombus or } \\
\text { encasement but } \\
\text { with suitable } \\
\text { vessel proximal } \\
\text { and distal to the } \\
\text { area of vessel } \\
\text { involvement, } \\
\text { allowing for safe } \\
\text { resection and } \\
\text { reconstruction }\end{array}$ & $\begin{array}{l}\text { Short-segment } \\
\text { occlusion with } \\
\text { suitable vessel above } \\
\text { and below; segmental } \\
\text { venous occlusion } \\
\text { alone without } \\
\text { SMA involvement } \\
\text { is rare and should } \\
\text { be apparent on CT } \\
\text { images }\end{array}$ & $\begin{array}{l}\text { Interface } \\
\text { between tumor } \\
\text { and vessel } \\
\text { measuring } \\
\geq 180^{\circ} \text { of the } \\
\text { circumference } \\
\text { of the vessel } \\
\text { wall, and/or } \\
\text { reconstructable } \\
\text { occlusion }\end{array}$ \\
\hline SMA & Tumor abutment & $\begin{array}{l}\text { Tumor } \\
\text { abutment } \\
\text { not to exceed } \\
>180^{\circ} \text { of the } \\
\text { circumference } \\
\text { of the vessel } \\
\text { wall }\end{array}$ & $\begin{array}{l}\text { Tumor abutment } \\
\text { of the SMA not to } \\
\text { exceed }>180^{\circ} \text { of } \\
\text { the circumference } \\
\text { of the vessel wall }\end{array}$ & $\begin{array}{l}\text { Tumor abutment } \\
>180^{\circ} \text { ( } \leq \text { one-half) of } \\
\text { circumference of the } \\
\text { artery; periarterial } \\
\text { stranding and tumor } \\
\text { points of contact } \\
\text { forming a convexity } \\
\text { against the vessel } \\
\text { improve chances of } \\
\text { resection }\end{array}$ & $\begin{array}{l}\text { Interface } \\
\text { between tumor } \\
\text { and vessel } \\
\text { measuring } \\
<180^{\circ} \text { of the } \\
\text { circumference of } \\
\text { the vessel wall }\end{array}$ \\
\hline $\begin{array}{l}\text { GDA } \\
\text { CHA }\end{array}$ & $\begin{array}{l}\text { Encasement up to } \\
\text { origin at hepatic } \\
\text { artery }\end{array}$ & $\begin{array}{l}\text { Encasement } \\
\text { up to the } \\
\text { hepatic artery } \\
\text { with either } \\
\text { short-segment } \\
\text { encasement } \\
\text { or direct } \\
\text { abutment of } \\
\text { the hepatic } \\
\text { artery, } \\
\text { without } \\
\text { extension of } \\
\text { the celiac axis }\end{array}$ & $\begin{array}{l}\text { Gastroduodenal } \\
\text { artery encasement } \\
\text { up to the hepatic } \\
\text { artery with either } \\
\text { short-segment } \\
\text { encasement or } \\
\text { direct abutment } \\
\text { of the hepatic } \\
\text { artery, without } \\
\text { extension to the } \\
\text { celiac axis }\end{array}$ & $\begin{array}{l}\text { Short-segment } \\
\text { encasement/ } \\
\text { abutment of the } \\
\text { common artery } \\
\text { (typically at the } \\
\text { gastroduodenal } \\
\text { origin); the surgeon } \\
\text { should be prepared } \\
\text { for vascular resection/ } \\
\text { interposition grafting }\end{array}$ & $\begin{array}{l}\text { Reconstructable, } \\
\text { short-segment } \\
\text { interface } \\
\text { between tumor } \\
\text { and vessel of any } \\
\text { degree }\end{array}$ \\
\hline $\begin{array}{l}\text { Celiac } \\
\text { trunk }\end{array}$ & No involvement & $\begin{array}{l}\text { No } \\
\text { involvement }\end{array}$ & No involvement & No involvement & $\begin{array}{l}\text { Interface } \\
\text { between tumor } \\
\text { and vessel } \\
<180^{\circ} \text { of the } \\
\text { circumference of } \\
\text { the vessel wall }\end{array}$ \\
\hline
\end{tabular}

Abbreviations: AHPBA, Americas Hepato-Pancreato-Biliary Association; CHA, common hepatic artery; GDA, gastroduodenal artery; PV, portal vein; SMA, superior mesenteric artery; SMV, superior mesenteric vein. 
planes around the celiac axis, hepatic artery, and superior mesenteric artery (SMA) and no radiologic evidence of SMV or PV distortion. Alternately, radiologic findings of venous involvement of the SMV or PV, with distortion or narrowing of the vein or occlusion of the vein with suitable vessel proximal and distal to the site of involvement, allowing for safe resection and replacement, characterize a tumor as borderline resectable. ${ }^{4}$ As for arterial involvement, radiologic findings of encasement of a short segment of the hepatic artery, without evidence of tumor extension to the celiac axis and/or tumor abutment of the SMA involving $180^{\circ}$ or less of the artery circumference, classify a tumor as borderline resectable. ${ }^{4}$

In 2013, a more restrictive definition of borderline resectable PDAC was put forth by the experts who designed the inclusion criteria for the Alliance A021101 trial, ${ }^{5}$ the first NCI-supported multi-institutional treatment trial for patients with borderline resectable PDAC. This definition uses the degree of contact described as the interface between tumor and blood vessels rather than subjective terms such as abutment and impingement. The NCCN panel has endorsed this definition for use in clinical trials.

In contrast to the use of only the relationship of the tumor to surrounding vasculature to define borderline resectable PDAC, the group from MD Anderson has used 2 additional distinct criteria to define borderline resectable PDAC. ${ }^{6}$ In this definition, patients with borderline resectable type $B$ disease have potentially resectable anatomy with clinical findings suspicious but not diagnostic for extrapancreatic disease, including indeterminate liver lesions, serum carbohydrate antigen (CA) 19-9 level of $1000 \mathrm{U} / \mathrm{mL}$ or greater (with a normal total bilirubin level), or biopsyproven involvement of regional lymph nodes. Patients with borderline resectable type $\mathrm{C}$ disease have potentially resectable anatomy with advanced age ( $\geq 80$ years), severe comorbidities requiring extensive evaluation or optimization, or depressed performance status $(\mathrm{ECOG} \geq 2)$.

Although the NCCN panel agreed that patients with metastases to nodes beyond the field of resection derive no benefit from resection, institutions differ in their approaches to peripancreatic lymph nodes. The NCCN panel recommends that patient factors be considered when deciding whether the patient is a surgical candidate. Patient age, comorbidities, performance status, and frailty are all things to be discussed during the multidisciplinary review. Treatment of older patients should follow the NCCN Guidelines for Older Adult Oncology (available at NCCN.org).

Patients commonly present to the oncologist with a non-pancreatic protocol CT already performed. The NCCN panel feels that, if the CT scan is not of high quality, a pancreatic protocol CT is recommended. The pancreatic protocol CT is the most widely available and best validated imaging modality for diagnosis and staging of patients with pancreatic cancer. ${ }^{7}$ Recently, a multidisciplinary expert consensus group defined standardized language for the reporting of imaging results. ${ }^{8}$ Uniform quality imaging and reporting can help improve the accuracy and consistency of identifying patients with borderline resectable PDAC. NCCN Member Institutions vary in the use of additional staging technologies, such as endoscopic ultrasound (EUS). The role of EUS staging is felt to be complementary to CT or MRI, providing additional information for patients whose initial scans show no lesion or whose lesions have questionable involvement of the vasculature or lymph nodes. However, the panel agreed that although the EUS has a high level of accuracy in assessing the involvement of certain vessels such as the $\mathrm{PV}$, this technique is less accurate in imaging tumor invasion of the SMA. ${ }^{9}$

Distinguishing resectable from borderline resectable pancreatic cancer is also important because of the sequencing of multimodality therapy. In the setting of borderline resectable disease, neoadjuvant therapy has been highly debated. However, although no randomized phase III trials support its use, most NCCN Member 
Institutions prefer an initial approach involving neoadjuvant therapy as opposed to immediate surgery for patients with borderline resectable disease. Although neoadjuvant therapy is also incorporated into the management of resectable disease at some institutions, most NCCN Member Institutions prefer upfront surgery in these patients. Some surgeons have questioned the inclusion of vein involvement in the definition of borderline resectable PDAC. In a multi-institutional retrospective study, they reported no difference in $\mathrm{R} 0$ resection in 70 patients who had vein resection and 422 patients who did not (66 vs $75 \% ; P=$ not significant) without neoadjuvant therapy..$^{10}$ In contrast, most institutional series report R0 resection rates of more than $90 \%$ in patients with borderline resectable PDAC receiving neoadjuvant therapy. ${ }^{11,12}$

The theoretical and practical advantages of a neoadjuvant approach in patients with borderline resectable PDAC include increasing the likelihood of a negative margin resection, potentially decreasing the number of pathologically involved lymph nodes in responsive patients, decreasing the likelihood of performing a vein resection, and identifying patients with poor tumor biology who experience disease progression during systemic therapy and therefore are unlikely to benefit from surgery. It is heartening that the many definitions of borderline resectable PDAC are converging. A uniform definition can help in assessing the varied approaches to these patients and help identify the most promising strategies for prospective studies designed to improve outcomes.

\section{References}

1. NCCN practice guidelines for pancreatic cancer. Oncology (Williston Park) 1997;11:41-55.

2. Tempero MA, Malafa MP, Behrman SW, et al. Pancreatic adenocarcinoma, version 2.2014: featured updates to the NCCN Guidelines. J Natl Compr Canc Netw 2014;12:1083-1093.

3. Callery MP, Chang KJ, Fishman EK, et al. Pretreatment assessment of resectable and borderline resectable pancreatic cancer: expert consensus statement. Ann Surg Oncol 2009;16:1727-1733.

4. Tempero MA, Malafa MP, Asburn H, et al. NCCN Clinical Practice Guidelines in Oncology: Pancreatic Adenocarcinoma. Version 2, 2015. Avaliable at: NCCN.org. Accessed May 1, 2015.

5. Katz MH, Marsh R, Herman JM, et al. Borderline resectable pancreatic cancer: need for standardization and methods for optimal clinical trial design. Ann Surg Oncol 2013;20:2787-2795.

6. Tzeng CW, Fleming JB, Lee JE, et al. Defined clinical classifications are associated with outcome of patients with anatomically resectable pancreatic adenocarcinoma treated with neoadjuvant therapy. Ann Surg Oncol 2012;19:2045-2053.

7. Wong JC, Lu DS. Staging of pancreatic adenocarcinoma by imaging studies. Clin Gastroenterol Hepatol 2008;6:1301-1308.

8. Al-Hawary MM, Francis IR, Chari ST, et al. Pancreatic ductal adenocarcinoma radiology reporting template: consensus statement of the society of abdominal radiology and the American Pancreatic Association Gastroenterology 2014;146:291-304.e1.

9. Buchs NC, Chilcott M, Poletti PA, et al. Vascular invasion in pancreatic cancer: Imaging modalities, preoperative diagnosis and surgical management. World J Gastroenterol 2010;16:818-831.

10. Kelly KJ, Winslow E, Kooby D, et al. Vein involvement during pancreaticoduodenectomy: is there a need for redefinition of "borderline resectable disease"? J Gastrointest Surg 2013;17:1209-1217; discussion 1217.

11. Ferrone CR, Marchegiani G, Hong TS, et al. Radiological and surgical implications of neoadjuvant treatment with FOLFIRINOX for locally advanced and borderline resectable pancreatic cancer. Ann Surg 2015;261:12-17.

12. Mellon EA, Hoffe SE, Springett GM, et al. Long-term outcomes of induction chemotherapy and neoadjuvant stereotactic body radiotherapy for borderline resectable and locally advanced pancreatic adenocarcinoma. Acta Oncol 2015:1-7.

13. Varadhachary GR, Tamm EP, Abbruzzese JL, et al. Borderline resectable pancreatic cancer: definitions, management, and role of preoperative therapy. Ann Surg Oncol 2006;13:1035-1046. 